\title{
Projecting malaria hazard from climate change in eastern Africa using large ensembles to estimate uncertainty
}

\author{
Joseph Leedale, ${ }^{1}$ Adrian M. Tompkins, ${ }^{2}$ Cyril Caminade, ${ }^{3}$ Anne E. Jones, ${ }^{3}$ Grigory Nikulin, ${ }^{4}$ \\ Andrew P. Morse ${ }^{1,5}$ \\ 'School of Environmental Sciences, University of Liverpool, Liverpool, UK; ${ }^{2}$ Abdus Salam \\ International Centre for Theoretical Physics, Trieste, Italy; ${ }^{3}$ Department of Epidemiology \\ and Population Health, Institute of Infection and Global Health, University of Liverpool, \\ Liverpool, UK; ${ }^{4}$ Rossby Centre, Swedish Meteorological and Hydrological Institute, \\ Norrköping, Sweden; ${ }^{5}$ National Institute for Health Research, Health Protection Research \\ Unit in Emerging and Zoonotic Infections, Liverpool, UK
}

\begin{abstract}
The effect of climate change on the spatiotemporal dynamics of malaria transmission is studied using an unprecedented ensemble of climate projections, employing three diverse bias correction and downscaling techniques, in order to partially account for uncertainty in climate-driven malaria projections. These large climate ensembles drive two dynamical and spatially explicit epidemiological malaria models to
\end{abstract}

Correspondence: Joseph Leedale, School of Environmental Sciences, University of Liverpool, Liverpool L69 3GE, UK.

Tel: +44.151.7950382.

E-mail: j.leedale@liverpool.ac.uk

Key words: Malaria; Climate change; Vector-borne disease; Climate model ensemble; Eastern Africa.

Acknowledgements: the authors acknowledge funding support from the HEALTHY FUTURES EU-FP7 project (grant agreement 266327). We acknowledge CORDEX, CMIP5, the Climate System Analysis Group at the University of Cape Town and the Inter-Sectoral Impact Model Intercomparison Project Fast Track project that was funded by the German Federal Ministry of Education and Research with project funding reference number 01LS1201 for provision of climate model data. CC also acknowledges support by The Farr Institute for Health Informatics Research (MRC grant: MR/M0501633/1).

Conflict of interest: the authors declare no potential conflict of interest.

Received for publication: 24 June 2015.

Revision received: 21 December 2015.

Accepted for publication: 21 December 2015.

(C) Copyright J. Leedale et al., 2016

Licensee PAGEPress, Italy

Geospatial Health 2016; 11(s1):393

doi:10.4081/gh.2016.393

This article is distributed under the terms of the Creative Commons Attribution Noncommercial License (CC BY-NC 4.0) which permits any noncommercial use, distribution, and reproduction in any medium, provided the original author(s) and source are credited. provide future hazard projections for the focus region of eastern Africa. While the two malaria models produce very distinct transmission patterns for the recent climate, their response to future climate change is similar in terms of sign and spatial distribution, with malaria transmission moving to higher altitudes in the East African Community (EAC) region, while transmission reduces in lowland, marginal transmission zones such as South Sudan. The climate model ensemble generally projects warmer and wetter conditions over EAC. The simulated malaria response appears to be driven by temperature rather than precipitation effects. This reduces the uncertainty due to the climate models, as precipitation trends in tropical regions are very diverse, projecting both drier and wetter conditions with the current state-of-the-art climate model ensemble. The magnitude of the projected changes differed considerably between the two dynamical malaria models, with one much more sensitive to climate change, highlighting that uncertainty in the malaria projections is also associated with the disease modelling approach.

\section{Introduction}

Malaria is one of the most well-studied vector-borne diseases in terms of present day transmission and potential for change in future climates. Studies have often used statistical relationships between malaria transmission or vector occurrence and climate in order to project the potential future distribution of malaria transmission areas (Martens et al., 1995a, 1995b; Van Lieshout et al., 2004; Tonnang et al., 2010). One area of intense debate focused on the highlands of western Kenya where data appears to indicate an increase in epidemic frequency due to warming temperatures, although these studies also highlighted the need to account for non-climatic factors. There has been debate regarding the attribution of these changes to anthropogenic climate change since the 2000s. The debate divided opinion on whether the key determinant was climate change (Patz et al., 2002; Pascual et al., 2006) or non-climatic factors (Reiter, 2001; Hay et al., 2002a, 2002b). It is more likely to be a combination of both effects (Mouchet et al., 1998) as it is difficult to separate individual driving factors in this highly coupled system (Tompkins and Di Giuseppe, 2015). However, there is an increasing amount of evidence emerging that points to temperature changes favouring shifts in malaria transmission zones as seen in the increase of human malaria at higher alti- 
tude regions across the planet (Alonso et al., 2011; Omumbo et al., 2011; Caminade et al., 2014; Dhimal et al., 2014a, 2014b, 2014c; Siraj et al., 2014). There is also increasing evidence that climate change has already impacted the latitudinal and altitudinal ranges of avian malaria in wild birds (Garamszegi, 2011; Loiseau et al., 2012; Zamora-Vilchis et al., 2012). The controversial role of climate in driving $20^{\text {th }}$ century malaria changes was further highlighted by Gething et al. (2010), who point out that societal and economic development have restricted the geographical areas subject to malaria transmission against a backdrop of warming temperatures. Nevertheless, it is informative to study the potential climate impact on disease transmission in isolation from other factors, in order to understand how climate trends may have hindered or even helped global control and elimination efforts and offset or enhanced change due to socio-economic development. The complexity in the role of climate is important to stress, since climate change could also cause transmission to reduce or even cease in areas presently subject to transmission, either by pushing temperatures beyond the upper limits at which transmission occurs, or by reducing precipitation and therefore vector breeding site availability, or even by increasing the incidence of intense rainfall events which increases first stage larvae mortality (Paaijmans et al., 2007). Two recent reports using versions of the dynamical malaria models used in the present study clearly demonstrate this. Ermert et al. (2012) used the Liverpool Malaria Model (LMM) to show warming temperatures pushing malaria to higher altitudes, while reduced precipitation led to reduced transmission in the West African monsoon area. This study used a single regional cli-

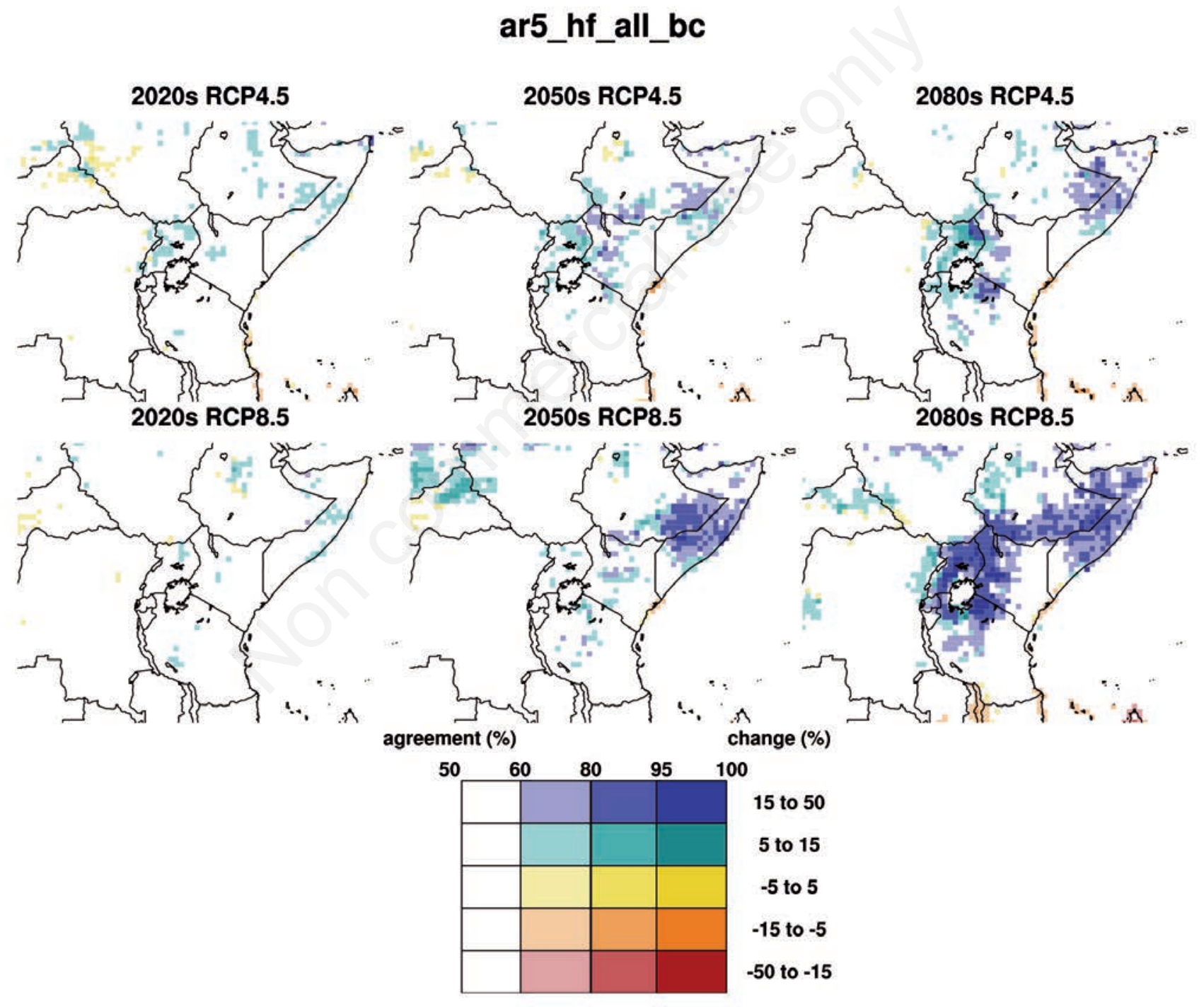

Figure 1. The effects of climate scenarios on simulated rainfall changes (super ensemble). Each map shows the results for a different emission scenario [representative concentration pathway (RCP) from moderate (RCP4.5) to most-severe (RCP8.5)] and a different time period. The different hues represent change in rainfall (\%) for the mean of the super ensemble with respect to the 1980-2005 historical mean. The different saturations represent sign agreement (\%) across the multi-model ensemble. ar5_, Intergovernmental Panel on Climate Change assessment report 5 (upon which future emission scenarios are based); _hf_, HEALTHY FUTURES; all_bc, ensemble average of all bias correction methods. 
mate model and a single malaria model and thus it was impossible to gauge the uncertainty associated with the use of different climate models in the study. The more recent work of Caminade et al. (2014) improved somewhat on this situation by employing five dynamical and statistical malaria models driven by five global climate models. The study repeated some of the conclusions of Ermert et al. (2012) but also highlighted the substantial disagreement between the disease models, in particular between those employing more complex dynamical and simpler rule-based methods. To improve the understanding of the relationship between climate drivers and disease a platform must be devel- oped such that disease transmission is modelled explicitly in time and space in response to changing climate and in some cases other environmental factors. In this report we focus on the impact of a changing climate on malaria using a large ensemble of latest generation global and regional climate projections conducted either for CMIP5, CORDEX or the HEALTHY FUTURES EU-FP7 project. The use of such a large and varied ensemble allows us to address the issues of uncertainty related to climate model formulation and provide the most detailed projections to date regarding the direct impact of climate change on malaria transmission in the east African highlands.

\section{ar5_hf_all_bc}

2020s RCP4.5

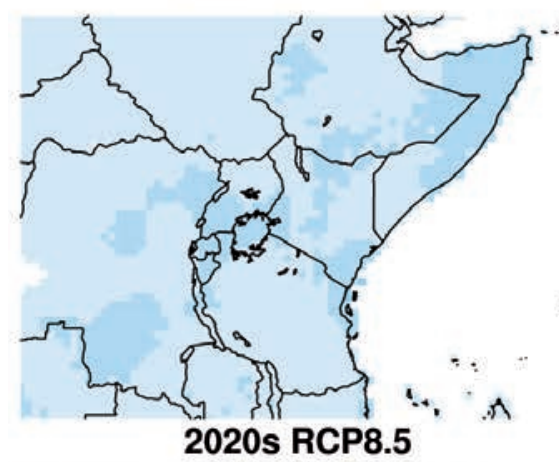

2050s RCP4.5

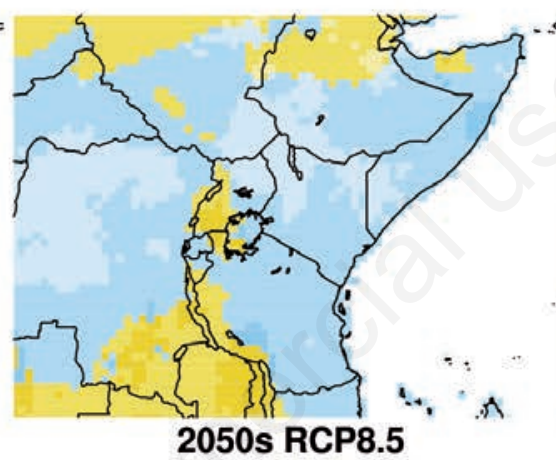

2080s RCP4.5

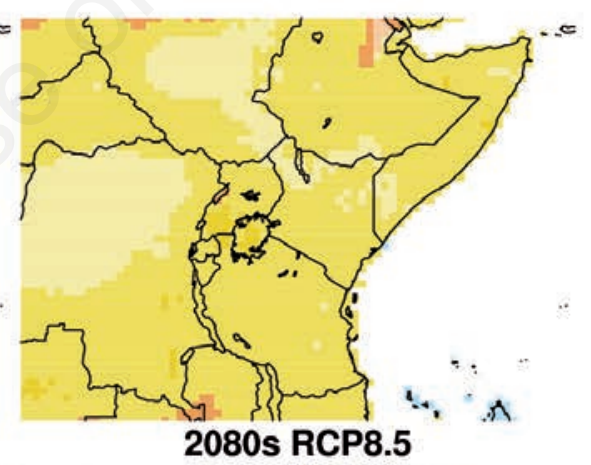

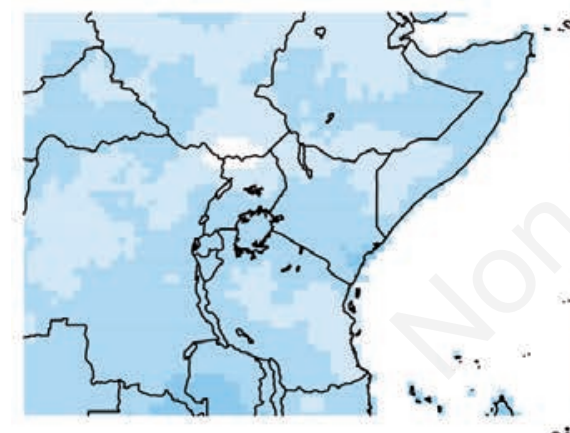

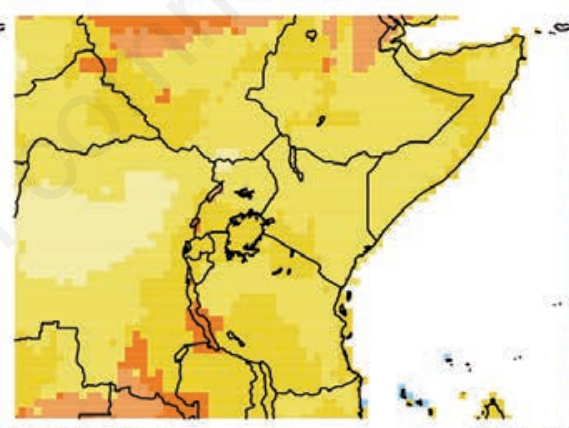

change (C)

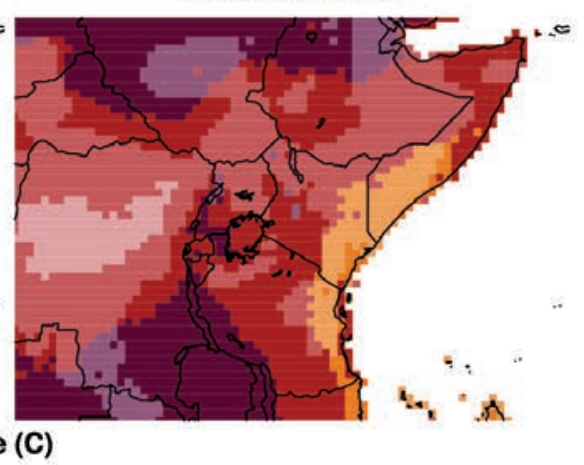

signal to noise

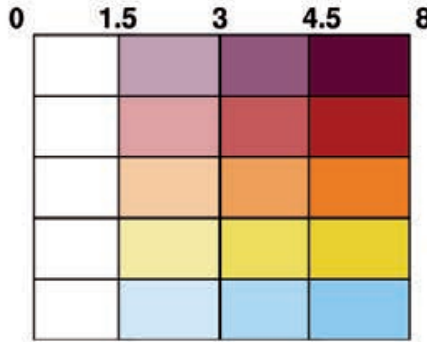

3.75 to 6

3 to 3.75

2.25 to 3

1.5 to 2.25

0 to 1.5

Figure 2. The effects of climate scenarios on simulated temperature changes (super ensemble). Each map shows the results for a different emission scenario [representative concentration pathway (RCP) from moderate (RCP4.5) to most-severe (RCP8.5)] and a different time period. The different hues represent change in temperature $\left({ }^{\circ} \mathrm{C}\right)$ for the mean of the super ensemble with respect to the $1980-2005$ historical mean. The different saturations represent signal-to-noise ratio $(\mu / \sigma)$ across the super ensemble (the noise is defined as one standard deviation within the multi-global climate model-regional climate model ensemble). ar5_, Intergovernmental Panel on Climate Change assessment report 5 (upon which future emission scenarios are based); _hf_, HEALTHY FUTURES; all_bc, ensemble average of all bias correction methods. 


\section{Materials and Methods}

\section{Overview of climate and environmental drivers}

Malaria is a parasitic disease caused by five forms of the Plasmodium parasite that is transmitted by Anopheles species mosquitoes to humans. In Africa, infections with the tropical form of the parasite, Plasmodium falciparum, are the most common and the most devastating for children of a young age, pregnant women and elders. It is this form of the parasite that is modelled in this study. Malaria epidemics occur in areas of unstable transmission when the disease is spread to vulnerable populations with low immunity. These epidemics generally occur at the fringes of endemic tropical regions such as the Sahel. The contribution of climate to malaria transmission is a significant determinant towards the spatial dynamics of the disease as both temperature and precipitation are key drivers of malaria. Precipitation provides the temporary breeding sites necessary for the Anopheles vec- tors to breed, while temperature affects the lifecycles of both the adult and immature vectors as well as the Plasmodium spp. parasite development rate in the adult vector after infection (Craig et al., 1999). Relative humidity impacts the vector activity and mortality rates, but to a lesser degree than temperature (Yamana and Eltahir, 2013), while wind speed is also thought to impact the ability of the female vector to track humans (Lindsay et al., 1995; Takken and Knols, 1999). However, this latter effect is poorly understood and is therefore neglected in the models used in this study.

\section{Disease modelling approaches}

Two disease models were employed to model malaria: the LMM (Hoshen and Morse, 2004), and the Vector-borne Disease Community Model of International Centre for Theoretical Physics Trieste (VECTRI) (Tompkins and Ermert, 2013). Both models employ a similar framework to model the adult and immature vector development, which is compartmental (i.e. development is recorded in a series of stages with-
C) LMM ar5_hf_cordex_bc

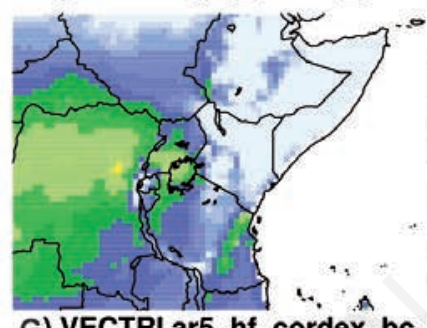

G) VECTRI ar5_hf_cordex_bc
D) LMM ar5_hf_isimip

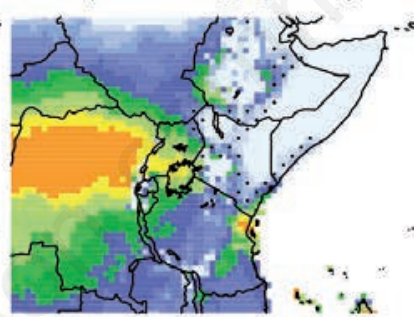

H) VECTRI ar5_hf_isimip
A) MAP2010

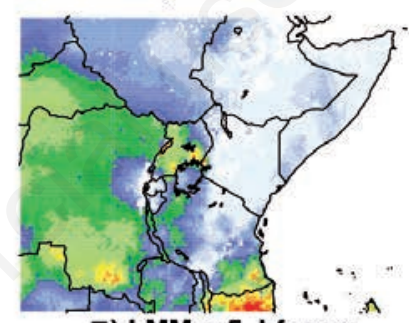

E) LMM ar5_hf_som
B) LMM-VECTRI ar5_hf_all_bc

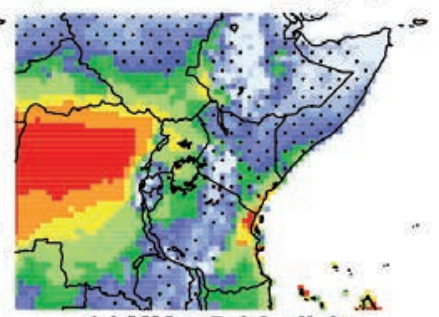

F) LMM ar5_hf_all_bc

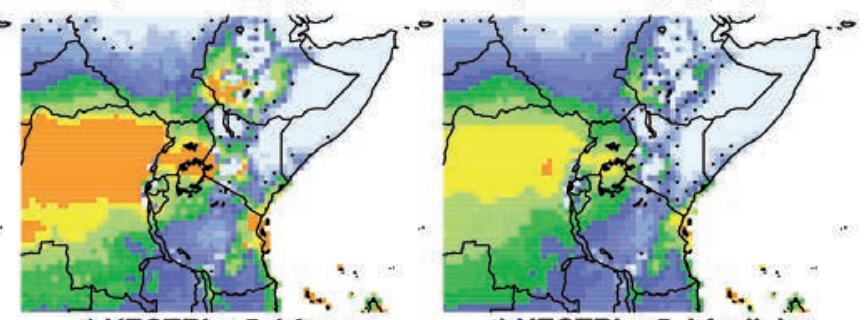

I) VECTRI ar5_hf_som

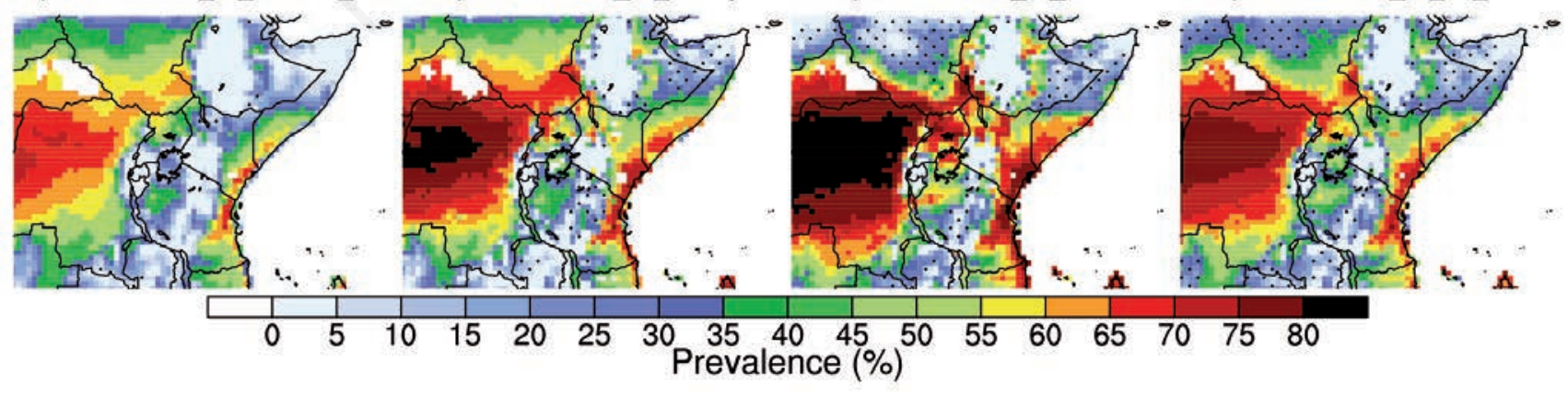

Figure 3. A) Malaria Atlas Project 2010 malaria prevalence and (B to J) simulated mean malaria prevalence based on climatic conditions (\%). This is carried out for the different HEALTHY FUTURES climate model ensembles for Liverpool Malaria Model (LMM), Vectorborne Disease Community Model of International Centre for Theoretical Physics Trieste (VECTRI) and a super summary (LMM-VECTRI). The ensemble mean of the historical experiments is shown for the period 1980-2005. The dotted area depicts regions where the ensemble mean is below two standard deviation of the multi-model ensemble (regions where the signal is noisy). ar5, Intergovernmental Panel on Climate Change assessment report 5 (upon which future emission scenarios are based); _hf_, HEALTHY FUTURES; all_bc, ensemble average of all bias correction methods; cordex, Coordinated Regional Downscaling Experiment; som, self organising map; Isimip, Inter-Sectoral Impact Model Intercomparison Project. 
in each spatial grid-cell). This approach allows the models to represent the delay between the rainy season and the malaria transmission peaks well. The LMM employs a linear relationship between rainfall and female egg-laying, while VECTRI represents the changing fractional coverage of small temporary pools with a simple surface hydrology model.

\section{Liverpool Malaria Model}

The LMM is an epidemiological model that has been formulated to describe the dynamics of malaria transmission and its dependence on climatic influences (rainfall and temperature). The model describes the evolution of population and transmission dynamics for both the mosquito vector (Anopheles spp.) and human host, with each population divided into susceptible, exposed and infectious classes.

A compartmental modelling approach is used to numerically solve the first order differential equations associated with the system, since some parameters controlling development rates vary as a function of the daily climate time-series used to drive the model. The mosquito population is modelled using larval and adult stages, with the number of eggs deposited into breeding sites depending on the previous ten days' (dekadal) rainfall. The larval mortality rate is also dependent on dekadal rainfall. Adult mosquito mortality rate and the egg-laying/biting (gonotrophic) cycle are dependent on temperature. In the malaria transmission component of the model, temperature dependencies occur in the rate of development of the parasite within the mosquito (sporogonic cycle) and the mosquito-biting rate. Both the sporogonic and gonotrophic cycles progress at a rate dependent on the number of degree-days above a specific temperature threshold. The gonotrophic cycle takes approximately 37 degree days with a threshold of $9^{\circ} \mathrm{C}$, whereas the sporogonic cycle takes approximately 111 degree days with a threshold of $18^{\circ} \mathrm{C}$ (for Plasmodium falciparum). This latter threshold is one of the most critical areas of sensitivity in the model, and below the threshold temperature no parasite development can occur. The LMM, driven by climate reanalysis, has been shown to be capable of
C) LMM ar5_hf_cordex_bc

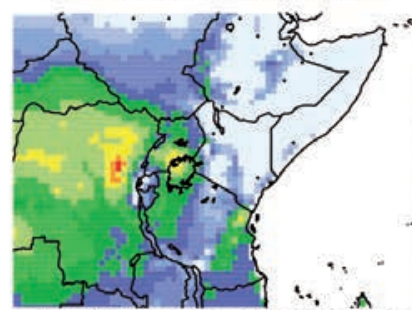

G) VECTRI ar5_hf_cordex_bc

\section{D) LMM ar5_hf_isimip}

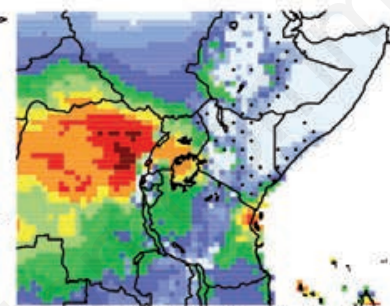

H) VECTRI ar5_hf_isimip
A) MARA 1980-2009

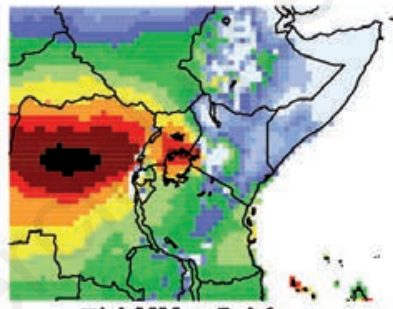

E) LMM ar5_hf_som
B) LMM-VECTRI ar5_hf_all_bc

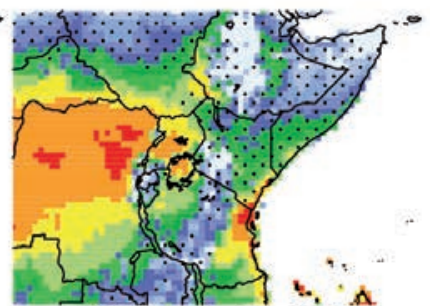

F) LMM ar5_hf_all_bc

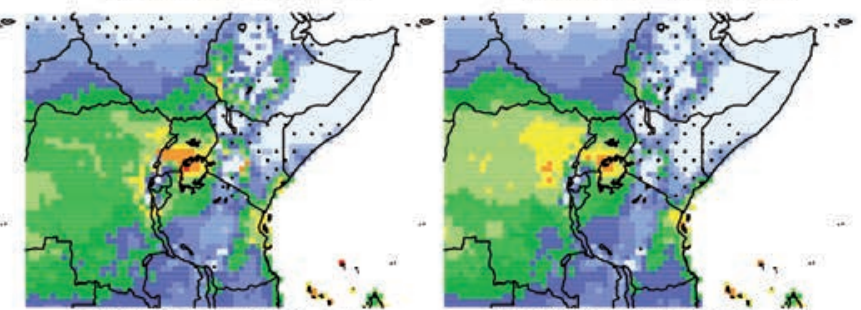

I) VECTRI ar5_hf_som

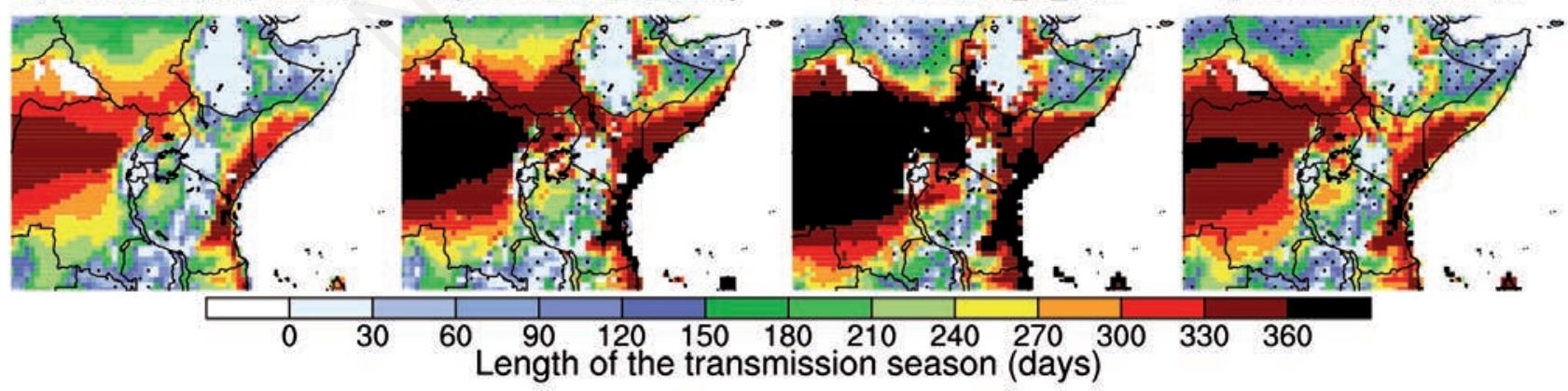

Figure 4. Simulated length of the malaria transmission season (days). This is carried out for the different HEALTHY FUTURES climate model ensembles (B to J) for Liverpool Malaria Model (LMM), Vector-borne Disease Community Model of International Centre for Theoretical Physics Trieste (VECTRI) and a super summary (LMM-VECTRI). The ensemble mean of the historical experiments is shown for the period 1980-2005. The dotted area depicts regions where the ensemble mean is below two standard deviation of the multi-model ensemble (regions where the signal is noisy). The Mapping Malaria Risk in Africa (MARA) model driven by the CRUTS3.1 climate observations (1980-2009) is shown for comparison purposes in (A). ar5_, Intergovernmental Panel on Climate Change assessment report 5 (upon which future emission scenarios are based); _hf_, HEALTHY FUTURES; all_bc, ensemble average of all bias correction methods; cordex, Coordinated Regional Downscaling Experiment; som, self organising map; Isimip, Inter-Sectoral Impact Model Intercomparison Project. 
simulating the inter-annual variability of malaria in Botswana, as compared against a 20-year anomaly index of the disease derived from malaria observations (Thomson et al., 2005), and has been used to evaluate the potential for malaria early warning using seasonal climate forecasts as driving conditions (Jones and Morse, 2010, 2012; MacLeod et al., 2015).

Vector-borne Disease Community Model of International Centre for Theoretical Physics Trieste

The VECTRI is a different but related mathematical model for malaria transmission that accounts for the impact of temperature and rain- fall variability on the development cycles of the malaria vector in its larval and adult stage, and also of the parasite itself. The majority of the relationships are taken from the literature for the Anopheles gambiae vector and the Plasmodium falciparum species of the parasite. Temperature affects the sporogonic and gonotrophic cycle development rates, as well as the mortality rates for adult vectors.

Rainfall effects on transmission are represented by a simple, physically-based model of surface pool hydrology, where low rainfall rates increase available breeding sites that decay through evaporation and infiltration, while intense rainfall events decrease early stage larvae through flushing (Tompkins and Ermert, 2013; Asare et al., 2016). The

\section{LMM-VECTRI ar5_hf_all_bc}
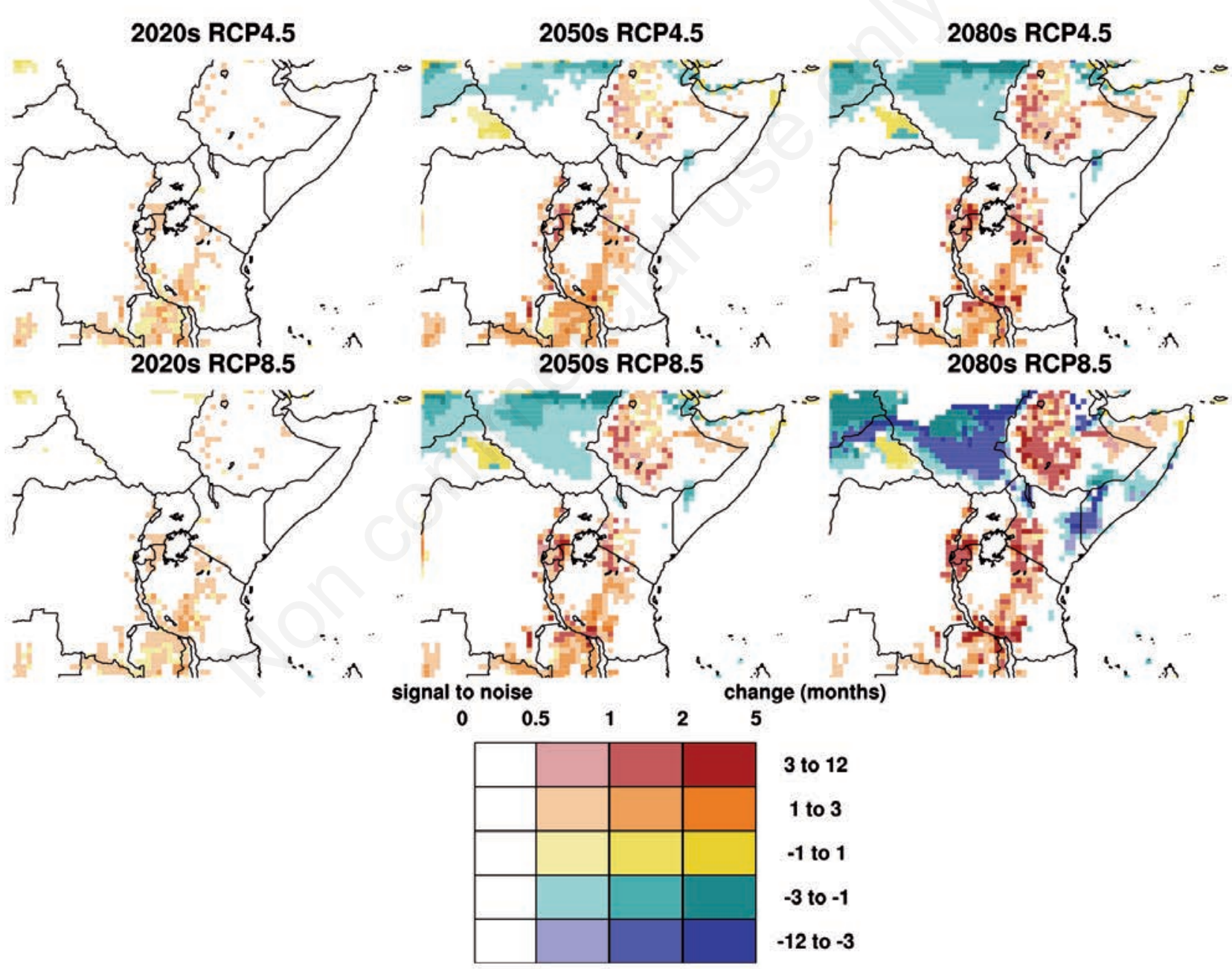

3 to 12

1 to 3

-1 to 1

-3 to -1

-12 to -3

Figure 5. The effect of climate scenarios on future malaria distribution: changes in length of the malaria season. Each row shows the results for a different emission scenario [representative concentration pathway (RCP) from moderate (RCP4.5) to most-severe (RCP8.5)]. The different hues represent change in the length of the transmission season between future time slices (2020s, e.g. 2016-2025; 2050s, e.g. 20462055; and 2080s, e.g. 2076-2085) and 1980-2005 for the ensemble mean of all bias-corrected experiments. The different saturations represent signal-to-noise ratio $(\mu / \sigma)$ across the super ensemble (the noise is defined as one standard deviation within the multi-global climate model and multi-malaria ensemble). This is carried out for two malaria models [Liverpool Malaria Model (LMM) and Vector-borne Disease Community Model of International Centre for Theoretical Physics Trieste (VECTRI)]. ar5_, Intergovernmental Panel on Climate Change assessment report 5 (upon which future emission scenarios are based); _hf,, HEALTHY FUTURES; all_bc, ensemble average of all bias correction methods. 
scheme presently uses a global calibration of the catchment fraction in each grid-cell, which neglects spatial topographical variations. VECTRI accounts for human population density in the calculation of biting rates, allowing it to be used to represent differences between urban, periurban and rural transmission rates. Higher population densities can lead to a dilution effect resulting in lower parasite ratios in urban and peri-urban environments compared with nearby rural locations. In this respect the model is able to reproduce the reduction in EIR and PR with population density that has been widely observed in field observations in Africa (Kelly-Hope and McKenzie, 2009). Future population growth could potentially reduce transmission intensity in VECTRI if included, but this effect is precluded in the present simulations for compatibility with the LMM experiments. Population density is thus fixed at present day values using the high-resolution spatial maps of Afripop (Linard $e t$ al., 2012). The model is designed for regional to continental scales at high spatial resolutions of up to a maximum of 5 to $10 \mathrm{~km}$. Full details of the model's mathematical framework and some evaluation of version v1.2.6 are given in Tompkins and Ermert (2013). The simulations conducted here use v1.3.2 which implements the sensitivity of the larvae growth stage to water temperature, which is assumed equal to air temperature, and impacts both the growth rate and mortality of larvae using the relationships of Craig et al. (1999) and Bayoh and Lindsay (2003). In addition, the larvae flushing effect is increased by reducing the efolding constant from 50 to $20 \mathrm{~mm}$ per day in order to better fit the

\title{
LMM ar5_hf_all_bc
}
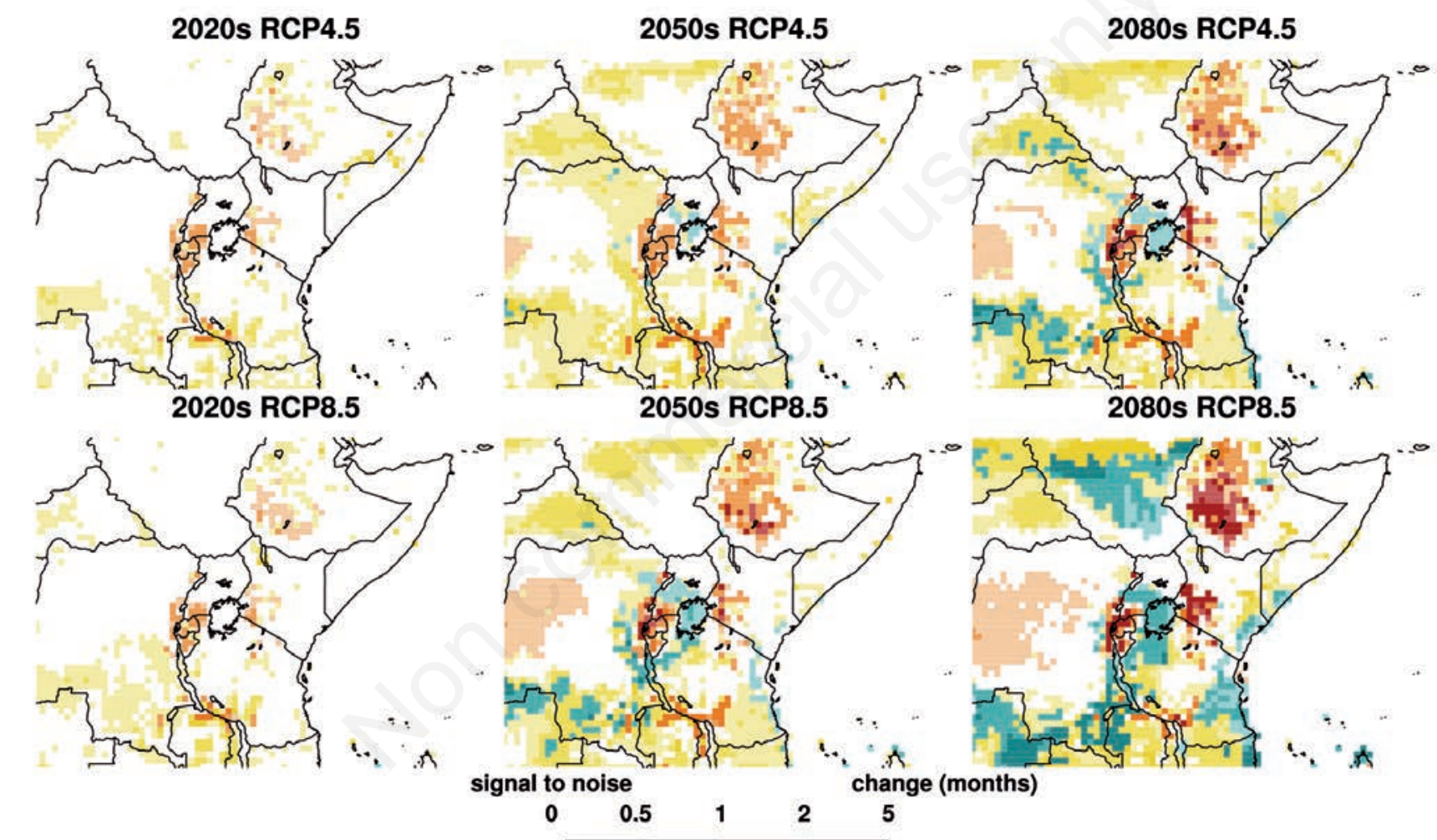

2050s RCP8.5
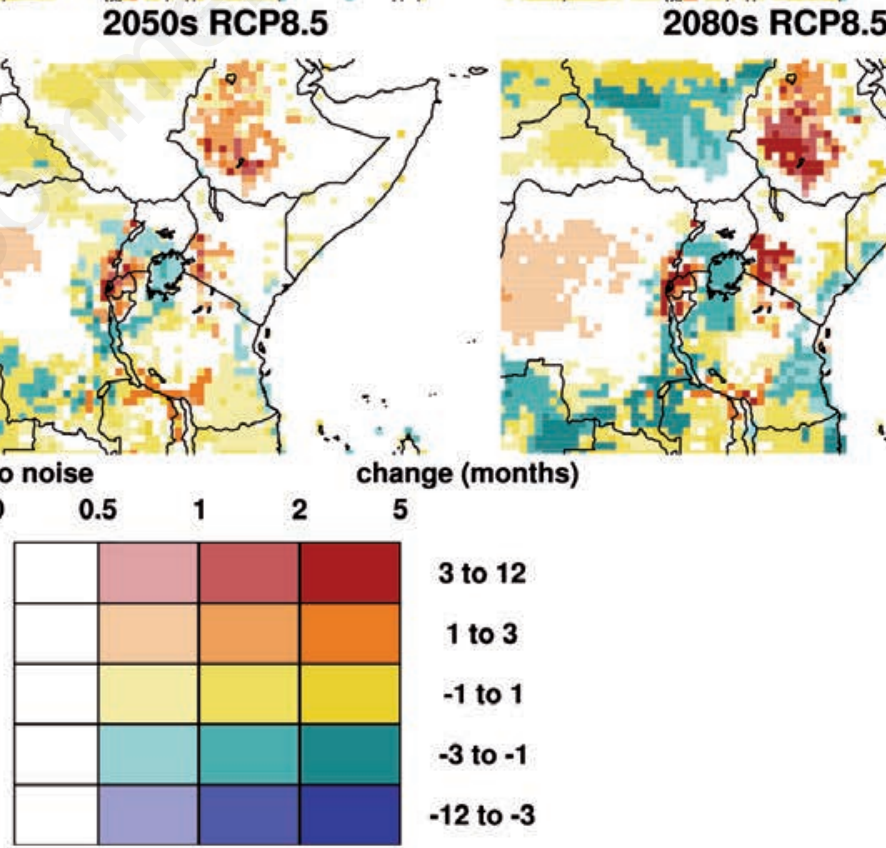

3 to 12

1 to 3

-1 to 1

-3 to -1

-12 to -3

\begin{abstract}
Figure 6. The effect of climate scenarios on future malaria distribution: changes in length of the malaria season. Each row shows the results for a different emission scenario [representative concentration pathway (RCP) from moderate (RCP4.5) to most-severe (RCP8.5)]. The different hues represent change in the length of the transmission season between future time slices (2020s, e.g. 20162025; 2050s, e.g. 2046-2055; and 2080s, e.g. 2076-2085) and 1980-2005 for the ensemble mean of all bias-corrected experiments. The different saturations represent signal-to-noise ratio $(\mu / \sigma)$ across the super ensemble (the noise is defined as one standard deviation within the multi-globl climate model and multi-malaria ensemble). This is carried out for the Liverpool Malaria Model (LMM). ar5_, Intergovernmental Panel on Climate Change assessment report 5 (upon which future emission scenarios are based); hf_, HEALTHY FUTURES; all_bc, ensemble average of all bias correction methods.
\end{abstract}


monthly relationship between cases and monthly rainfall reported in Thomson et al. (2006) and Lowe et al. (2013).

\section{Malaria metrics}

As VECTRI explicitly accounts for population density and can represent differences between urban, peri-urban and rural transmission rates, person-month-at-risk statistics can differ substantially between the two modelling systems. For example, VECTRI has been able to model lower transmission intensities in areas of high population density in western Africa such as peri-urban Bobo-Dioulasso, Burkina Faso (Tompkins and Ermert, 2013). Thus, in order to facilitate intercompar- ison of the two malaria models only, the basic disease parameters of prevalence [parasite ratio (PR)], entomological inoculation rate (EIR, infective bites per person per day) and length of transmission season (LTS, in days) are used in the analysis. The LTS is arbitrarily defined as the total number of days for which the EIR rate exceeds 0.01 per day, to match former estimates (Caminade et al., 2014).

\section{Climate and environmental data}

The dynamical malaria models require daily input data for rainfall and temperature and in the case of VECTRI, socio-economic and land cover conditions.

\section{VECTRI ar5_hf_all_bc}
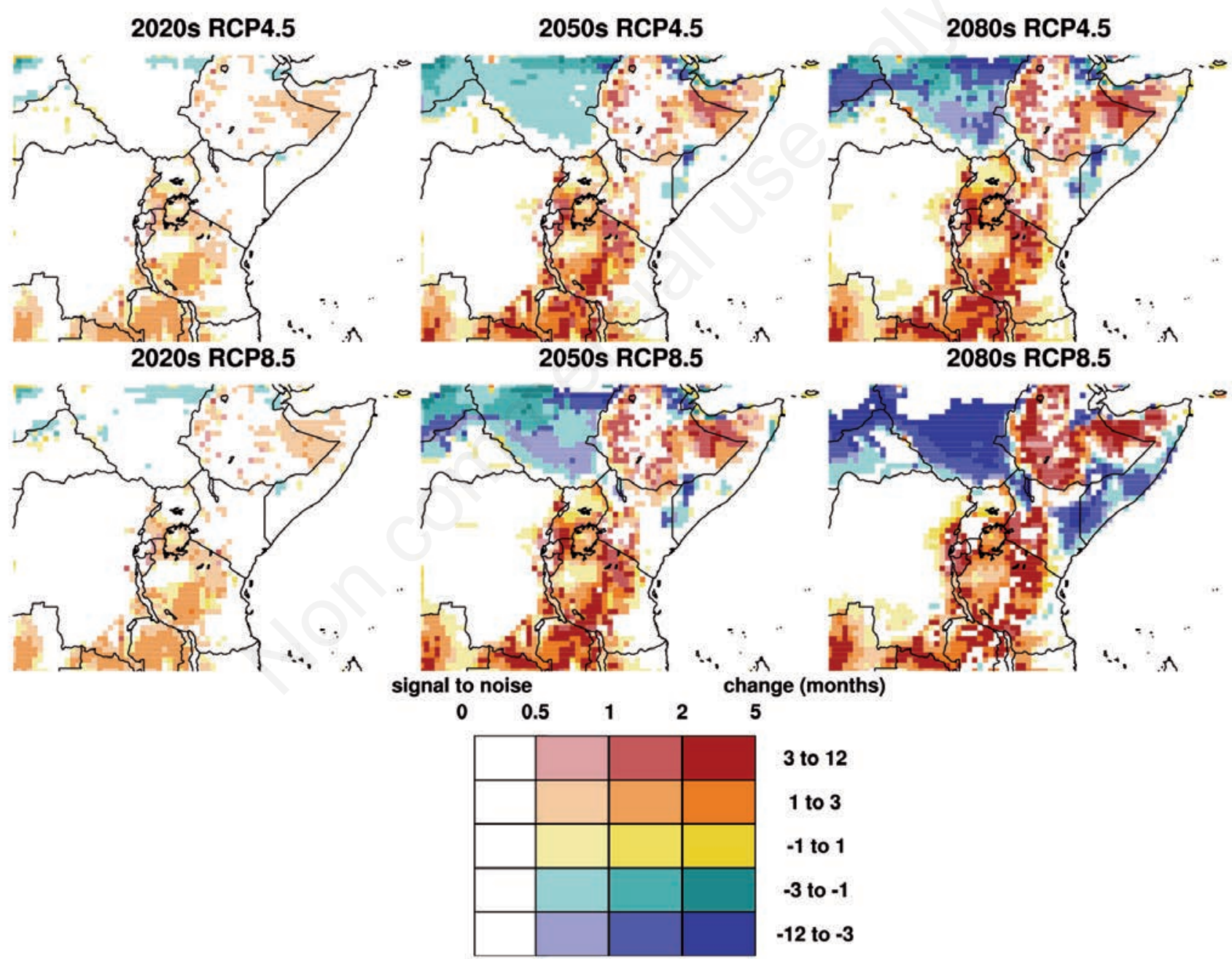

3 to 12

1 to 3

-1 to 1

-3 to -1

-12 to -3

Figure 7. The effect of climate scenarios on future malaria distribution: changes in length of the malaria season. Each row shows the results for a different emission scenario [representative concentration pathway (RCP) from moderate (RCP4.5) to most-severe (RCP8.5)]. The different hues represent change in the length of the transmission season between future time slices (2020s, e.g. 2016-2025; 2050s, e.g. 20462055; and 2080s, e.g. 2076-2085) and 1980-2005 for the ensemble mean of all bias-corrected experiments. The different saturations represent signal-to-noise ratio $(\mu / \sigma)$ across the super ensemble (the noise is defined as one standard deviation within the multi-global climate model and multi-malaria ensemble). This is carried out for the Vector-borne Disease Community Model of International Centre for Theoretical Physics Trieste (VECTRI) malaria model. ar5, Intergovernmental Panel on Climate Change assessment report 5 (upon which future emission scenarios are based); _hf_, HEALTHY FUTURES; all_bc, ensemble average of all bias correction methods. 


\section{Climate input}

This study uses the largest and most varied collection of global and regional climate model output yet assembled to assess climate-health interactions. The global projection stream is based on five global climate models (GCMs) that stem from the latest round of the Climate Model Intercomparison Project Phase 5 (CMIP5), which contributed directly to the recent Intergovernmental Panel on Climate Change (IPCC) $5^{\text {th }}$ assessment report. These five models were selected for the Inter-Sectoral Impact Model Intercomparison Project (ISI-MIP) (Warszawski et al., 2014). Two ensemble streams present the regional projections. The first regional stream is based on an ensemble of eight CMIP5 GCMs dynamically downscaled by a regional climate model (SMHI-RCA4) at $50 \mathrm{~km}$ resolution over Africa within the African branch of the Coordinated Regional Downscaling Experiment (CORDEX). The second regional stream is based on an ensemble of ten CMIP5 GCMs statistically downscaled by the self-organising map (SOM) based downscaling method (Hewitson and Crane, 2006) at $50 \mathrm{~km}$ resolution over eastern Africa in the HEALTHY FUTURES project.

Climate models suffer from biases (errors) in their representation of mean and variability of observed climate and bias correction using observations for adjustment is necessary before conducting malaria model integrations. The 5 CMIP5 GCMs in ISI-MIP are interpolated to a common 0.5-degree grid and then bias-corrected using a methodology created in ISI-MIP (Hempel et al., 2013). The dynamically downscaled CORDEX-Africa simulations are bias-corrected by the distributionbased scaling (DBS) method (Yang et al., 2010). All these streams are available for the representative concentration pathways RCP4.5 and RCP8.5, representing moderate and most-severe greenhouse gas concentration scenarios (Moss et al., 2010), and the ISI-MIP stream (Hempel et al., 2013) is available for all four RCPs (2.6, 4.5, 6.0, 8.5). The three ensembles are illustrated and detailed in Table 1. One caveat to note when assessing future climate change is that only one realisa- tion (initial conditions) was conducted for each global model in all three ensembles. This means that uncertainties related to natural variability cannot be accessed in the present study. Recent work with large ensembles has indicated that these uncertainties can be significant in the first half of the $21^{\text {st }}$ century, after which scenario uncertainty dominates (Hawkins and Sutton, 2009; Thompson et al., 2014; Xie et al., 2015). Therefore in the following it should be recalled that climate model uncertainty refers to the model and not to uncertainty related to natural variability. Analysis was performed on these multi-model malaria hazard projections by calculating the mean, spread (standard deviation) and relative differences in time (anomalies) for the various streams and different future time slices, e.g. 2020s (2016-2025), 2050s (2046-2055) and 2080s (2076-2085). Anomalies were calculated using the respective historical baseline for 1980-2005.

\section{Results}

The rainfall changes for the two RCPs are shown in Figure 1 for a selection of decades spread across the $21^{\text {st }}$ century. Rainfall is simulated to increase over the EAC region for the future. The precipitation changes are comparable between RCP4.5 and RCP8.5, albeit with a stronger signal in RCP8.5 relative to RCP4.5. However, there is much disagreement between the various climate model streams in the majority of the eastern Africa region. Specific regions where there appear to be more general agreement in precipitation include areas of western Kenya, Uganda, southeast Ethiopia and Somalia, where most models appear to project future increases in rainfall to varying degrees.

There is far more agreement in the overall temperature increase simulated across eastern Africa (Figure 2), with greater warming occurring over the border regions to the north and south of the EAC

Table 1. Overview of the climate modelling streams used and bias correction methods involved.

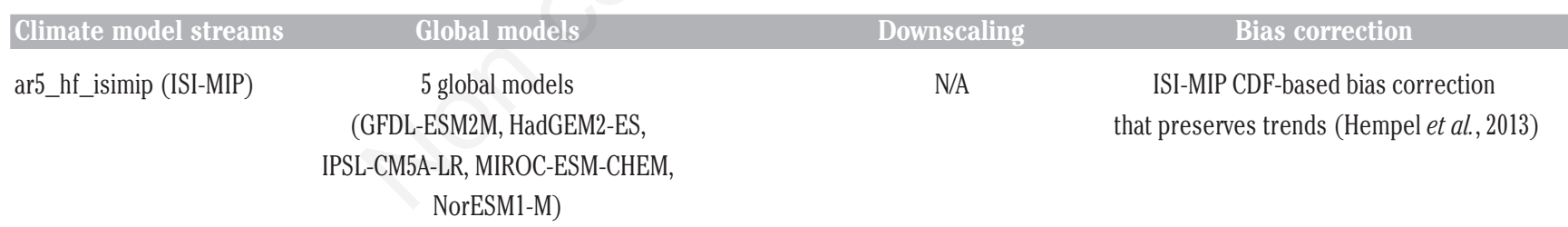

\begin{tabular}{|c|c|c|c|}
\hline ar5_hf_som (SOM) & $\begin{array}{c}10 \text { global models } \\
\text { (BNU-ESM, CNRM-CM5, CanESM2, } \\
\text { FGOALS-s2, GFDL-ESM2G, } \\
\text { GFDL-ESM2M, MIROC-ESM-CHEM, } \\
\text { MIROC-ESM, MRI-CGCM3, BCC-CSM1-1) }\end{array}$ & $\begin{array}{l}\text { SOM downscaling using large-scale } \\
\text { predictors (Hewitson and Crane, 2006) }\end{array}$ & N/A \\
\hline $\begin{array}{l}\text { ar5_hf_cordex_bc } \\
\text { (CORDEX) }\end{array}$ & $\begin{array}{c}8 \text { global models } \\
\text { (CanESM2, CNRM-CM5, HadGEM2-ES, } \\
\text { NorESM1-M, EC-EARTH, MIROC5, } \\
\text { GFDL-ESM2M, MPI-ESM-LR) }\end{array}$ & $\begin{array}{l}1 \text { regional model } \\
\text { SMHI-RCA4 }\end{array}$ & $\begin{array}{l}\text { DBS bias correction } \\
\text { (Yang et al., 2010) by SMHI }\end{array}$ \\
\hline $\begin{array}{l}\text { ar5_hf_all_bc } \\
\text { (SUPER ENSEMBLE) }\end{array}$ & $\begin{array}{l}\text { Super ensemble average } \\
\text { interpolated on the } \\
\text { ISI-MIP grid ( } 23 \text { members) }\end{array}$ & $\mathrm{N} / \mathrm{A}$ & $\mathrm{N} / \mathrm{A}$ \\
\hline \multicolumn{4}{|c|}{$\begin{array}{l}\text { ar5_, Intergovernmental Panel on Climate Change assessment report } 5 \text { (upon which future emission scenarios are based); hf_, HEALTHY FUTURES; ISI-MIP, Inter-Sectoral Impact Model Intercomparison Project; } \\
\text { GFDL-ESM2M, Geophysical Fluid Dynamics Laboratory - Earth System Model 2M; HadGEM2-ES, Met Office Hadley Global Environment Model } 2 \text { - Earth System; IPSL-CM5A-LR, Institut Pierre Simon Laplace - Modelling } \\
\text { Centre 5A - Low resolution; MIROC-ESM-CHEM, atmospheric chemistry coupled version of MIROC-ESM; MIROC-ESM, Model for Interdisciplinary Research on Climate - Earth System Model; NorESM1-M, Norwegian } \\
\text { Earth System Model 1-M; N/A, not available; ISI-MIP CDF, ISI-MIP cumulative distribution function; SOM, self organising map; BNU-ESM, Beijing Normal University Earth System model; CNRM-CM5, Centre National de } \\
\text { Recherches Météorologiques - CM5; CanESM2, Canadian Earth System Model 2; FGOALS-s2, Flexible Global Ocean-Atmosphere-Land System model, Spectral Version 2; GFDL-ESM2G, Geophysical Fluid Dynamics } \\
\text { Laboratory - Earth System Model 2G; MRI-CGCM3, Meteorological Research Institute - Coupled Global Climate Model 3; BCC-CSM1-1, Beijing Climate Center Climate System Model 1-1; CORDEX, Coordinated Regional } \\
\text { Downscaling Experiment; EC-EARTH, European Centre - Earth; MIROC5, Model for Interdisciplinary Research on Climate 5; MPI-ESM-LR, Max Planck Institute for Meteorology - Earth System Model - Low resolution; } \\
\text { SMHI-RCA4, Swedish Meteorological and Hydrological Institute - Rossby Centre regional atmospheric model, version 4; DBS, distribution based scaling; all_bc, ensemble average of all bias correction methods. }\end{array}$} \\
\hline
\end{tabular}


region of interest. Only the central regions of the Congo rainforest in the Democratic Republic of Congo and northern South Sudan exhibit large uncertainty in both precipitation and temperature changes. The RCP8.5 experiments provide a stronger signal for the increase in temperature compared to RCP4.5 as expected. The majority of the EAC region is projected to increase in temperature by at least $3^{\circ} \mathrm{C}$ by the 2080s. Such high changes are expected to have considerable impacts on transmission of vector-borne diseases such as malaria.

The different malaria simulations carried out for the historical period (1980 to 2005) are compared with the Malaria Atlas Project 2010 $\left(\mathrm{MAP}_{2010}\right)$ statistical model analysis developed by Gething et al. (2011). This model combines available field data of parasite ratio (PR) with key climate and socio-economic predictors to produce high resolution modelling maps of PR for the 2 to 10 year age range using a Bayesian modelling framework (Figure 3). This dataset is based on malaria observations; however this is still a statistical model output, and it is only used as an external data source to compare with our malaria model outputs. Both VECTRI and LMM tend to overestimate malaria endemicity over central Africa, Ethiopia, the southern coasts of Kenya and the southeastern coasts of Somalia. This overestimation appears stronger in VECTRI compared to the LMM. Part of the overestimation is due to the lack of certain processes in the malaria models, which are further detailed in the discussion, in addition to the fact that malaria interventions are not accounted for.

The multi-model spread (uncertainty) in prevalence is generally highest near the epidemic fringes of the distribution, for low prevalence values. The local maximum over southern Tanzania is better reproduced by VECTRI with, however, a large overestimation in magnitude. The northern fringe of the malaria distribution is also better reproduced by VECTRI over northern Sudan (not shown). Generally, LMM shows a better agreement with $\mathrm{MAP}_{2010}$ in terms of magnitude. It should be noted that the signal provided by the CORDEX climate model stream is translated into more realistic prevalence values by the disease models when compared to $\mathrm{MAP}_{2010}$. Simulated LTS values are shown for comparison between LMM, VECTRI and the Mapping Malaria Risk in Africa (MARA) distribution model (Tanser et al., 2003) driven by CRUTS3.1 observed climate data (Harris et al., 2014) (Figure 4). VECTRI generally overestimates LTS, particularly at the eastern coastline, while LMM simulates shorter transmission seasons than those predicted by MARA in the Congo. The CORDEX climate model provides the best signal in terms of capturing the LTS quantities in this region for VECTRI, while it is the ISI-MIP stream that yields the best output for LMM. Switching between different climate model streams can have different effects on the scale and direction of change in LTS depending on the disease model used. Whereas with historical prevalence the SOM climate stream generally provided the largest signals for LMM and VECTRI (Figure 3), when SOM signals are used to produce LTS values VECTRI simulates seasons longer than those associated with any other climate and LMM simulates its shortest (Figure 4). This relationship hints at an effect of climate on EIR and the arbitrary threshold used to determine LTS.

The impact of future climate change on the simulated length of the malaria transmission season is shown for LMM-VECTRI (Figure 5), LMM (Figure 6) and VECTRI (Figure 7). This is carried out based on the super climate ensemble of all climate models for two scenarios (RCP4.5 and RCP8.5) and for different time slices (2020s, 2050s, 2080s). The results (Figure 5) generally agree with previous research (Alonso et al., 2011; Omumbo et al., 2011) and the recent multi-model ensemble results of Caminade et al. (2014) regarding the spatial shift of malaria to the highlands. The climate becomes increasingly suitable for malaria transmission over the highlands of eastern Africa, namely the plateaux of Ethiopia, western Kenya, southern Uganda, Rwanda, Burundi and across the centre of Tanzania (Figure 5). The LMM (Figure 6) and VECTRI (Figure 7) results separately show similar dynamic trends but at different scales, with LMM changes smaller in magnitude compared with VECTRI. This is also consistent with the stronger overestimation of malaria prevalence by VECTRI during the historical period. Climatic suitability increases over a large part of the Ethiopian highlands based on LMM, while according to VECTRI this is more restricted to the edges of the highlands (Figure 7). A clear decrease in the simulated length of the transmission season is also shown over South Sudan, particularly for VECTRI driven by the RCP8.5 emission scenario, due to the projected increases in average temperature. This simulated decrease over the northern marginal fringes of malaria transmission is consistent with the estimates of former studies (Ermert et al., 2012; Caminade et al., 2014).

\section{Discussion}

Climate-driven models of malaria provide a quantitative method of considering the impact of climate on malaria transmission solely. The HEALTHY FUTURES project used the largest and most varied collection of global and regional climate projections to drive two disease models and evaluate the impact of climate change on malaria transmission for the EAC region. This study has helped to establish and develop a platform for major impact modelling intercomparison exercises, alongside other recent work in the field (Kienberger and Hagenlocher, 2014; Warszawski et al., 2014; Hagenlocher and Castro, 2015). This platform allows for the integration of long-term projections of climate under various future scenarios with dynamic epidemiological models to provide a large ensemble of predictive climate-related malaria hazard in eastern Africa over the next century. This research employed two established malaria models (LMM and VECTRI), two of the common RCPs (4.5 and 8.5), and three separate streams of future climate projections comprising a total of 23 climate model experiments. This allowed the investigation of uncertainties related to different disease modelling approaches, different concentration scenarios, different global climate models and different downscaling methodologies (dynamical and statistical).

Dynamic malaria models tend to overestimate malaria prevalence values generated by the $\mathrm{MAP}_{2010}$ model over the EAC region with respect to other estimates when the epidemiology is driven solely by climatic factors. For example, in highly endemic areas of central Africa, immunity is already partly established in the 2 to 10 year age range, while the models both presently neglect immunity. It should also be recalled that many areas in the East African Community (EAC) region have been subject to a significant scaling up of interventions in the recent period, some of which started prior to 2010. For example, Tompkins and Ermert (2013) highlighted the east coast of Kenya where the field studies in the $1980 \mathrm{~s}$ and $1990 \mathrm{~s}$ show typical malaria prevalence ranging from 0.3 to 0.8 (Mbogo et al., 2003), while a concerted campaign of insecticidetreated net (ITN) distribution has greatly reduced transmission more recently (Okiro et al., 2007; 0'Meara et al., 2008), with the result that $\mathrm{MAP}_{2010}$ diagnoses a prevalence of around 0 to $20 \%$. The malaria models only account for climate and therefore simulate prevalence values much closer to the pre-intervention period. This highlights the importance of understanding the modelling approaches taken when comparing disease models, which are generally derived from the particular questions under investigation (Johnson et al., 2014).

Projections of the impact of climate on malaria dynamics reveal 
more consistency between different ensemble members and models for the higher emissions scenarios towards the end of the timescale, i.e. where climate change (particularly temperature increase) is predicted to be the most severe. The chief contribution to uncertainty between simulations appears to be the different methodologies and assumptions made within the disease models themselves, particularly with respect to the effects of temperature on vectors. Mordecai et al. (2013) showed that optimal temperatures for malaria transmission could potentially be lower than previously published estimates, although the result is likely to be sensitive to the particular datasets used to fit each of the temperature-sensitive processes of the vector and larvae lifecycles, which are highly uncertain. For example, the VECTRI model has a higher peak transmission range of 27 to $32^{\circ} \mathrm{C}$ when compared to Mordecai et al. (2013) despite accounting for the identical set of larvae, parasite and adult vector temperature-sensitive processes (with the exception of female fecundity). Transmission falls to zero at approximately $39^{\circ} \mathrm{C}$ in VECTRI, rather than the $34^{\circ} \mathrm{C}$ value reported by Mordecai et al. (2013), even though the capping process of larvae mortality is identical in both models, further highlighting the large uncertainties involved in these parameterisation schemes. Examples can be found of transmission occurring at temperatures exceeding the limit of both models (Searle, 1920).

The largest differences between VECTRI, LMM and the model of Mordecai et al. (2013) are expected where temperature is projected to exceed $35^{\circ} \mathrm{C}$, since the latter model does not sustain transmission at these temperatures. This is especially found in the northern part of the EAC region. The temperature-dependent mortality of adult mosquitoes as reported by Martens et al. (1995a) was used in the survival probability function for LMM (Jones and Morse, 2010). This survival scheme appears even less permissive than the Mordecai estimates (at $35^{\circ} \mathrm{C}$, survival probability drops to $40 \%$ in LMM while the Mordecai estimates show $40 \%$ surviving at $42^{\circ} \mathrm{C}$ ). If we consider the final vectorial capacity estimate (Mordecai et al., 2013), which merges all epidemiological parameters relying on temperature, it is relatively close to the Martens scheme, which generally drives the final simulated LMM incidence decrease over the warmest regions. However, the Mordecai scheme is less permissive, e.g. vector competence drops to almost 0 at approximately $35^{\circ} \mathrm{C}$, while a threshold of about $40^{\circ} \mathrm{C}$ will have to be reached within LMM to produce similar effects. The importance of temperaturedependent vector survival probability previously motivated the analysis of multiple schemes and their relative sensitivity during development of LMM (Ermert et al., 2011) and VECTRI (Tompkins and Ermert, 2013).

All modelling combinations in the present study generally agree on the increase in climate suitability for malaria transmission over the eastern African highlands of the Rift Valley and Ethiopia in the future. This supports other findings in previous research depicting the spatial impact of climate change on malaria (Caminade et al., 2014; Dhimal et al., 2014a; Siraj et al., 2014). The supporting results of Caminade et al. (2014) were based on a greater malaria model ensemble (including MARA, MIASMA and UMEA) using fewer climate model inputs as drivers (five GCMs were used whereas here we combined different GCMs, one regional climate model and one empirical-statistical downscaling method). There also appears to be general agreement between models in projecting a southward shift of the epidemic fringe that lies over the northern fringe of the Sudano-Sahelian region.

Despite differences in the modelling methodologies and climate signals used to drive each numerical simulation, some overarching conclusions can still be made. Common aspects of the modelling results emerging from this research are the significant impact that climate drivers have on transmission dynamics and crucially, the noticeable effect of climate change on future disease hazard dynamics. These models have predicted long-term shifts in spatial hazard dynamics for malaria when changes in local environmental conditions are applied leading to the emergence of vector niches in previously unaffected and immunologically naive regions. However, this warning should be viewed in the appropriate context of the original research questions posed. Generally, these models consider the impact climate has on shaping the spatial variation in disease susceptibility while neglecting other external factors important in determining whether or not a particular disease is capable of thriving and driving epidemic or endemic behaviour. Therefore these results provide a method to estimate projected hazard (climate-related disease susceptibility) while other vulnerability factors (e.g. surface hydrology, socio-economic factors, landuse changes, etc.) are required in order to gain a more complete picture of the overall projected malaria risk across eastern Africa (Kienberger and Hagenlocher, 2014).

Climate data provide the fundamental forcing signal that drives the epidemiological dynamics of the disease models. Data provided by climate models inevitably varies across the different models due to uncertainty in the representation of atmospheric and other physical processes in the earth system models. These inter-modelling system variations that lead to a spread in climate projection data are subsequently added to by uncertainties associated with downscaling methodologies and bias correction techniques. Combined with uncertainties in the impacts model used for malaria transmission, the result is a cascade of uncertainty. For example, in contrast to the recent drying trend observed in the region (Williams and Funk, 2011; Diem et al., 2014), most of the climate models used in this study project an increase in precipitation in large areas (Figure 1) highlighting the importance in communicating potential differences between short-term variability and simulated longer term trends to decision makers. Climate model uncertainty is evident in this study where we use a wide ensemble of climate data collected from various global climate models and regional downscaling techniques in acknowledgment of this issue. This ensemble intercomparison method currently offers the best means of providing a comprehensive projection of climate-based scenarios but represents a crude assessment of uncertainty since, in contrast to numerical weather prediction where ensemble predictions can be evaluated against observations over many integrations, for climate projections there is no known way of assessing whether the ensembles generated are under or over confident. For example, uncertainty due to processes neglected in the present study is not accounted for, such as uncertainty due to future potential land use change (Tompkins and Caporaso, 2016), population movement and changes, economic growth or other socioeconomic conditions that will be critical for the African continent. The predictive value of studying the impact of climate in isolation on disease transmission and drawing associated conclusions about its relationship with non-climatic factors separately is debatable. A combined modelling study is certainly a way forward for more predictive modelling. However, our dynamical model framework requires estimates of the driving data for both the recent context and the future. Population changes were considered in Caminade et al. (2014) using the Shared Socioeconomic Pathway 2 population scenario provided by the International Institute for Applied Systems Analysis.

\section{Conclusions}

Future estimates of vector control measures and new technologies, e.g. vaccines, are impossible to predict. All indirect effects of climate 
change on population migration will also play a role, however these will be highly hypothetical and very difficult to model and anticipate precisely. Note that recent work carried out by the World Bank combined results from Caminade et al. (2014) with economic projections to assess future malaria risks (Hallegatte et al., 2016). Béguin et al. (2011) also show that socio-economic development might counteract the expected negative effects of climate change on malaria. Future improvements in modelling techniques to include such effects in a coupled modelling system should ultimately lead to more accurate assessments of potential future malaria risk. However, these scenarios will still be undermined by the possibility of bio-technological breakthroughs (e.g. the development of cost-efficient vaccines and novel control techniques) that might occur during the following decades.

\section{References}

Alonso D, Bouma MJ, Pascual M, 2011. Epidemic malaria and warmer temperatures in recent decades in an East African highland. P Roy Soc B-Biol Sci 278:1661-9.

Asare E, Tompkins A, Amekudzi L, Ermert V, 2016. A breeding site model for regional, dynamical malaria simulations evaluated using in situ temporary ponds observations. Geospat Health 11:390.

Bayoh MN, Lindsay SW, 2003. Effect of temperature on the development of the aquatic stages of Anopheles gambiae sensu stricto (Diptera: Culicidae). B Entomol Res 93:375-81.

Béguin A, Hales S, Rocklöv J, Åström C, Louis VR, Sauerborn R, 2011. The opposing effects of climate change and socio-economic development on the global distribution of malaria. Global Environ Chang 21:1209-14.

Caminade C, Kovats S, Rocklov J, Tompkins AM, Morse AP, ColónGonzález FJ, Stenlund H, Martens P, Lloyd SJ, 2014. Impact of climate change on global malaria distribution. P Natl Acad Sci USA 111:3286-91.

Craig MM, Snow RW, Le Sueur D, 1999. A climate-based distribution model of malaria transmission in sub-Saharan Africa. Parasitol Today 15:105-11.

Dhimal M, Ahrens B, Kuch U, 2014a. Altitudinal shift of malaria vectors and malaria elimination in Nepal. Malaria J 13:P26.

Dhimal M, Ahrens B, Kuch U, 2014b. Species composition, seasonal occurrence, habitat preference and altitudinal distribution of malaria and other disease vectors in eastern Nepal. Parasite Vector 7:540.

Dhimal M, O'Hara RB, Karki R, Thakur GD, Kuch U, Ahrens B, 2014c. Spatio-temporal distribution of malaria and its association with climatic factors and vector-control interventions in two high-risk districts of Nepal. Malaria J 13:457.

Diem JE, Ryan SJ, Hartter J, Palace MW, 2014. Satellite-based rainfall data reveal a recent drying trend in central equatorial Africa. Climatic Change 126:263-72.

Ermert V, Fink AH, Jones AE, Morse AP, 2011. Development of a new version of the Liverpool Malaria Model. I. Refining the parameter settings and mathematical formulation of basic processes based on a literature review. Malaria J 10:35.

Ermert V, Fink AH, Morse AP, Paeth H, 2012. The impact of regional climate change on malaria risk due to greenhouse forcing and landuse changes in tropical Africa. Environ Health Persp 120:77.

Garamszegi LZ, 2011. Climate change increases the risk of malaria in birds. Glob Change Biol 17:1751-9.

Gething PW, Patil AP, Smith DL, Guerra CA, Elyazar I, Johnston GL,
Tatem AJ, Hay SI, 2011. A new world malaria map: Plasmodium falciparum endemicity in 2010. Malaria J 10:378.

Gething PW, Smith DL, Patil AP, Tatem AJ, Snow RW, Hay SI, 2010. Climate change and the global malaria recession. Nature 465:342-5.

Hagenlocher M, Castro MC, 2015. Mapping malaria risk and vulnerability in the United Republic of Tanzania: a spatial explicit model. Popul Health Metr 13:2.

Hallegatte S, Bangalore M, Bonzanigo L, Fay M, Kane T, Narloch U, Rozenberg J, Treguer D, Vogt-Schilb A, 2016. Shock waves: managing the impacts of climate change on poverty. World Bank, Washington, DC, USA.

Harris I, Jones PD, Osborn T, Lister DH, 2014. Updated high resolution grids of monthly climatic observations: the CRU TS3. 10 Dataset. Int J Climatol 34:623-42.

Hawkins E, Sutton R, 2009. The potential to narrow uncertainty in regional climate predictions. B Am Meteorol Soc 90:1095-107.

Hay SI, Cox J, Rogers DJ, Randolph SE, Stern DI, Shanks GD, Myers MF, Snow RW, 2002a. Climate change and the resurgence of malaria in the East African highlands. Nature 415:905-9.

Hay SI, Rogers DJ, Randolph SE, Stern DI, Cox J, Shanks GD, Snow RW, 2002b. Hot topic or hot air? Climate change and malaria resurgence in East African highlands. Trends Parasitol 18:530-4.

Hempel S, Frieler K, Warszawski L, Schewe J, Piontek F, 2013. A trendpreserving bias correction: the ISI-MIP approach. Earth Syst Dynam 4:219-36.

Hewitson BC, Crane RG, 2006. Consensus between GCM climate change projections with empirical downscaling: precipitation downscaling over South Africa. Int J Climatol 26:1315-38.

Hoshen MB, Morse AP, 2004. A weather-driven model of malaria transmission. Malaria J 3:32.

Johnson LR, Lafferty KD, McNally A, Mordecai E, Paaijmans KP, Pawar S, Ryan SJ, 2014. Mapping the distribution of malaria: current approaches and future directions. In: Chen D, Moulin B, Wu J, eds. Analyzing and modeling spatial and temporal dynamics of infectious diseases. John Wiley \& Sons, New York, NY, USA, pp 189-209.

Jones AE, Morse AP, 2012. Skill of ENSEMBLES seasonal re forecasts for malaria prediction in West Africa. Geophys Res Lett 39:L23707.

Jones AE, Morse AP, 2010. Application and validation of a seasonal ensemble prediction system using a dynamic malaria model. J Climate 23:4202-15.

Kelly-Hope LA, McKenzie FE, 2009. The multiplicity of malaria transmission: a review of entomological inoculation rate measurements and methods across sub-Saharan Africa. Malaria J 8:19.

Kienberger S, Hagenlocher M, 2014. Spatial-explicit modeling of social vulnerability to malaria in East Africa. Int J Health Geogr 13:29.

Linard C, Gilbert M, Snow RW, Noor AM, Tatem AJ, 2012. Population distribution, settlement patterns and accessibility across Africa in 2010. PloS One 7:e31743.

Lindsay SW, Armstrong-Schellenberg JRM, Zeiler HA, Daly RJ, Salum FM, Wilkins HA, 1995. Exposure of Gambian children to Anopheles gambiae malaria vectors in an irrigated rice production area. Med Vet Entomol 9:50-8.

Loiseau C, Harrigan RJ, Cornel AJ, Guers SL, Dodge M, Marzec T, Carlson JS, Seppi B, Sehgal RN, 2012. First evidence and predictions of Plasmodium transmission in Alaskan bird populations. PLoS One 7:e44729.

Lowe R, Chirombo J, Tompkins AM, 2013. Relative importance of climatic, geographic and socioeconomic determinants of malaria in Malawi. Malaria J 12:416.

MacLeod DA, Jones A, Di Giuseppe F, Caminade C, Morse AP, 2015. Demonstration of successful malaria forecasts for Botswana using 
an operational seasonal climate model. Environ Res Lett 10:044005.

Martens WJ, Jetten TH, Rotmans J, Niessen LW, 1995b. Climate change and vector-borne diseases: a global modelling perspective. Global Environ Chang 5:195-209.

Martens WJ, Niessen LW, Rotmans J, Jetten TH, McMichael AJ, 1995a. Potential impact of global climate change on malaria risk. Environ Health Persp 103:458.

Mbogo CM, Mwangangi JM, Nzovu J, Gu W, Yan G, Gunter JT, Swalm C, Keating J, Regens JL, Shililu JI, 2003. Spatial and temporal heterogeneity of Anopheles mosquitoes and Plasmodium falciparum transmission along the Kenyan coast. Am J Trop Med Hyg 68:734-42.

Mordecai EA, Paaijmans KP, Johnson LR, Balzer C, Ben Horin T, Moor E, McNally A, Pawar S, Ryan SJ, Smith TC, 2013. Optimal temperature for malaria transmission is dramatically lower than previously predicted. Ecol Lett 16:22-30.

Moss RH, Edmonds JA, Hibbard KA, Manning MR, Rose SK, Van Vuuren DP, Carter TR, Emori S, Kainuma M, Kram T, 2010. The next generation of scenarios for climate change research and assessment. Nature 463:747-56.

Mouchet J, Manguin S, Sircoulon J, Laventure S, Faye 0, Onapa AW, Carnevale P, Julvez J, Fontenille D, 1998. Evolution of malaria in Africa for the past 40 years: impact of climatic and human factors. J Am Mosquito Contr 14:121-30.

0'Meara WP, Bejon P, Mwangi TW, Okiro EA, Peshu N, Snow RW, Newton CR, Marsh K, 2008. Effect of a fall in malaria transmission on morbidity and mortality in Kilifi, Kenya. Lancet 372:1555-62.

Okiro EA, Hay SI, Gikandi PW, Sharif SK, Noor AM, Peshu N, Marsh K, Snow RW, 2007. The decline in paediatric malaria admissions on the coast of Kenya. Malaria J 6:151.

Omumbo JA, Lyon B, Waweru SM, Connor SJ, Thomson MC, 2011. Raised temperatures over the Kericho tea estates: revisiting the climate in the East African highlands malaria debate. Malaria $\mathrm{J}$ $10: 12$.

Paaijmans KP, Wandago M0, Githeko AK, Takken W, 2007. Unexpected high losses of Anopheles gambiae larvae due to rainfall. PLoS One 2:e1146.

Pascual M, Ahumada JA, Chaves LF, Rodo X, Bouma M, 2006. Malaria resurgence in the East African highlands: temperature trends revisited. P Natl Acad Sci USA 103:5829-34.

Patz JA, Hulme M, Rosenzweig C, Mitchell TD, Goldberg RA, Githeko AK, Lele S, McMichael AJ, Le Sueur D, 2002. Climate change (communication arising): regional warming and malaria resurgence. Nature 420:627-8.

Reiter P, 2001. Climate change and mosquito-borne disease. Environ Health Persp 109:141.

Searle C, 1920. Bilharziasis and malaria during the Palestine campaign. J R Army Med Corps 34:15-34.

Siraj AS, Santos-Vega MJ, Bouma M, Yadeta D, Carrascal DR, Pascual $\mathrm{M}, 2014$. Altitudinal changes in malaria incidence in highlands of Ethiopia and Colombia. Science 343:1154-8.
Takken W, Knols BG, 1999. Odor-mediated behavior of Afrotropical malaria mosquitoes. Annu Rev Entomol 44:131-57.

Tanser FC, Sharp B, Le Sueur D, 2003. Potential effect of climate change on malaria transmission in Africa. Lancet 362:1792-8.

Thompson DW, Barnes EA, Deser C, Foust WE, Phillips AS, 2014. Quantifying the role of internal climate variability in future climate trends. J Climate 28:6443-56.

Thomson M, Doblas-Reyes F, Mason S, Hagedorn R, Connor S, Phindela T, Morse A, Palmer T, 2006. Malaria early warnings based on seasonal climate forecasts from multi-model ensembles. Nature 439:576-9.

Thomson MC, Doblas-Reyes FJ, Mason SJ, Hagedorn R, Connor SJ, Phindela T, Morse AP, Palmer TN, 2006. Malaria early warnings based on seasonal climate forecasts from multi-model ensembles. Nature 439:576-9.

Tompkins A, Caporaso L, 2016. Assessment of malaria transmission changes in Africa, due to the climate impact of land use change using Coupled Model Intercomparison Project Phase 5 earth system models. Geospat Health 11:380.

Tompkins AM, Di Giuseppe F, 2015. Potential predictability of malaria in Africa using ECMWF monthly and seasonal climate forecasts. J Appl Meteorol Clim 54:521-40.

Tompkins AM, Ermert V, 2013. A regional-scale, high resolution dynamical malaria model that accounts for population density, climate and surface hydrology. Malaria J 12:65.

Tonnang HE, Kangalawe RY, Yanda PZ, 2010. Predicting and mapping malaria under climate change scenarios: the potential redistribution of malaria vectors in Africa. Malaria J 9:111.

Van Lieshout M, Kovats RS, Livermore MTJ, Martens P, 2004. Climate change and malaria: analysis of the SRES climate and socio-economic scenarios. Global Environ Chang 14:87-99.

Warszawski L, Frieler K, Huber V, Piontek F, Serdeczny 0, Schewe J, 2014. The Inter-Sectoral Impact Model Intercomparison Project (ISI-MIP): project framework. P Natl Acad Sci USA 111:3228-32.

Williams AP, Funk C, 2011. A westward extension of the warm pool leads to a westward extension of the Walker circulation, drying eastern Africa. Clim Dynam 37:2417-35.

Xie S-P, Deser C, Vecchi GA, Collins M, Delworth TL, Hall A, Hawkins NC, Cassou C, Giannini A, Watanabe M, 2015. Towards predictive understanding of regional climate change. Nat Clim Chang 5:921-30.

Yamana TK, Eltahir EA, 2013. Incorporating the effects of humidity in a mechanistic model of Anopheles gambiae mosquito population dynamics in the Sahel region of Africa. Parasite Vector 6:235.

Yang W, Andreasson J, Graham P, Olsson J, Rosberg J, Wetterhall F, 2010. Distribution-based scaling to improve usability of regional climate model projections for hydrological climate change impacts studies. Hydrol Res 41:211-29.

Zamora-Vilchis I, Williams SE, Johnson CN, 2012. Environmental temperature affects prevalence of blood parasites of birds on an elevation gradient: implications for disease in a warming climate. PLoS One 7:e39208. 